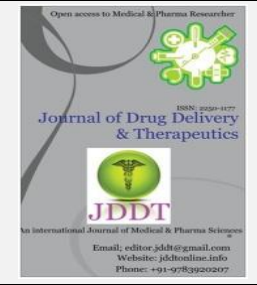

Open $\odot$ Access

Research Article

\title{
Anxiolytic Potency of Cardamonin Mediated through Brain GABAergic System
}

\author{
Rajput Mithun Singh *, Rathore Devashish, Dahima Rashmi \\ School of Pharmacy, Devi Ahilya Vishwavidyalaya, Takshashila Campus, Khandwa Road, Indore-452001, M.P., India
}

\begin{abstract}
Anxiety is an ailment causing personal, social and economic burden. Some drugs are available to provide symptomatic assistance for the treatment of anxiety and attempts are being made to find new therapeutic entities and subside associated adverse effects. Approaching natural sources, the current study aims to investigate the anxiolytic effects of cardamonin and its effect on the brain GABAergic system. The anxiolytic effects of various dose of cardamonin were investigated using the elevated plus maze apparatus and possible motor disabilities were evaluated trough open field test. Possible impact on GABAergic system was investigated using the ELISA. Fourteen days treatment with cardamonin (5.0 and $10.0 \mathrm{mg} / \mathrm{kg}$, i.p.) in mice significantly ( $\mathrm{p}<0.0001)$ increased and the percentages of open arm entry and open arm time compared to respective vehicle control group. Cardamonin show no influence on gross locomotor movement in open field test. Treatment with cardamonin significantly $(\mathrm{p}<0.0001)$ increased levels of GABA in brain of treated mice compared to control mice. This study provided evidence on the anxiolytic potency of the cardamonin and revealed its action mechanism of regulating the GABA level in mouse brain.
\end{abstract}

Keywords: Anxiety, Cardamonin, GABA

Article Info: Received 28 Nov 2018; Review Completed 06 Jan 2019; $\quad$ Accepted 09 Jan 2019; Available online 15 Jan 2019

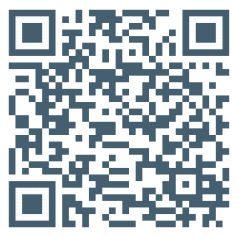

Cite this article as:

Rajput MS, Rathore D, Dahima R, Anxiolytic Potency of Cardamonin Mediated through Brain GABAergic System , Journal of Drug Delivery and Therapeutics. 2019; 9(1):248-251 DOI: http://dx.doi.org/10.22270/jddt.v9i1.2322

\section{*Address for Correspondence:}

Dr. Mithun Singh Rajput, Postdoctoral Fellow, School of Pharmacy, Devi Ahilya Vishwavidyalaya, Takshashila Campus, Khandwa Road, Indore-452001, M.P., India.

\section{INTRODUCTION}

Nervous ailments particularly depression and anxiety are predominant all over the world, that affect the value of daily lives and enhance the risk for additional medical complications. It is projected that by 2020 such behavioral disorder will account for about $15 \%$ of the universal burden of disease ${ }^{1}$. Anxiety has been defined as "a psychological and physiological state characterized by somatic, emotional, cognitive and behavioral components". It is an emotional state, unpleasant in nature, associated with uneasiness, discomfort and fear about some defined or undefined future threat 2 . The personal, social and economic expenditures linked with this mental disorder is noticeably high. Some drugs are available to provide appropriate symptomatic assistance for the treatment of anxiety; however these are associated with ample adverse effects like ataxia, drug dependence, drowsiness, withdrawal syndrome, drug interactions etc ${ }^{3}$. Attempts are being made to find new therapeutic entities and subside these adverse effects. Subsequently, there is excessive interest in exploration of appropriate and harmless agents from natural source and in the recent years; progresses are being made in this regard 4.

Cardamonin, chemically known as (2', 4'-dihydroxy-6'methoxychalcone) is a naturally occurring chalcone, ISSN: 2250-1177 foremost isolated from seeds of Amomum subulatum and later from other plant species, such as Alpinia henryi, Alpinia katsumadai, Alpinia rafflesiana, Boesenbergia pandurata and Campomanesia adamantium ${ }^{5}$. Cardamonin is known to exhibit many pharmacological activities including antiinflammatory, anti-mutagenic, anti-neoplastic, antiproliferative, anti-tumor, in vitro anti-HIV, vasorelaxant, hypoglycemic, anti-infectious and anti-platelet activities ${ }^{6}$. It is also known to possess potential beneficial effects on various neurological disorders including anti-nociceptive property ${ }^{6}$, neuroprotection of PC12 cells against oxidative damage 7 and ameliorative effect on hyperalgesia and allodynia in a mouse model of chronic constriction injuryinduced neuropathic pain ${ }^{8}$. The quest for potential health applications of cardamonin particularly in relation to neuroprotection seems to grow in the near future as shown clearly by the increasing number of ongoing research. The current study was carried out with the aim to investigate the anxiolytic effects of cardamonin and the effect on cardamonin on the brain GABAergic system.

\section{MATERIALS AND METHODS}

\section{Animals}




\section{Rajput et al}

Adult Swiss albino mice (25-30 g) were used in this study. One week period was given to the animals to acclimatize to the new environment $\left(25 \pm 5{ }^{\circ} \mathrm{C}, 50 \pm 5 \%\right.$ humidity and a 12/12-h light/dark cycle starting at 08:00 A.M. Food and water were provided ad libitum. Seven days acclimatization was provided to the animals before start of experiment. All the experiments were carried out according to the animal care guidelines as provided by National Institute of Health and after getting authorization from Institutional Animal Ethics Committee constituted as per the guidelines of CPCSEA.

\section{Drugs and solutions}

Cardamonin or 2', 4'-dihydroxy-6'-methoxychalcone with the purity of $\geq 98 \%$, dimethyl sulphoxide (DMSO), tween 20 and estazolam was purchased from Sigma Aldrich (SigmaAldrich Chemicals Pvt. Ltd. Bengaluru, India). Cardamonin was freshly prepared by dissolving in DMSO, tween 20 and distilled water at a ratio of 5:5:90 (v/v). Estazolam (6 mg) was suspended in $0.5 \%$ sodium CMC aqueous solution in a $100 \mathrm{ml}$ constant volume [8]. All other drugs were dissolved in distilled water. The doses for all freshly prepared drug solutions were expressed in terms of their free bases.

\section{Treatment schedule}

The animals were randomly allocated into various groups of six mice each. Animals of group I served as vehicle control and treated with vehicle for cardamonin $(1 \mathrm{ml} / \mathrm{kg}$, i.p.). Mice of group II, III and IV were treated with cardamonin at the dose of 2.5, 5.0 and $10.0 \mathrm{mg} / \mathrm{kg}$, i.p. respectively and group V served as standard and treated with estazolam $(1.5 \mathrm{mg} / \mathrm{kg}$, p.o.) once daily for fourteen days. Behavioral tests were conducted on the fourteenth day after three hours of last treatment.

\section{Evaluation of antianxiety activity}

Elevated plus maze test (EPM)

The plus maze was composed of two open arms $(42.5 \mathrm{~cm} \times$ $10.0 \mathrm{~cm})$ and two closed arms $(42.5 \mathrm{~cm} \times 10.0 \mathrm{~cm} \times 22.5 \mathrm{~cm})$, extending from a central platform $(10.0 \mathrm{~cm} \times 10.0 \mathrm{~cm})$ and elevated to a height of $50.0 \mathrm{~cm}$ above the floor. The entire maze was made of clear Plexiglas. Mice were individually placed in the center of the maze facing an open arm. Arm entries were defined as the placement of all four paws into an arm. Animal activities were recorded during a $5 \mathrm{~min}$ observation period, including the number of open and closed arm entries (OE and $\mathrm{CE}$ ), the duration in open and closed arms (OT and CT) and the percentages of open arm entry
Journal of Drug Delivery \& Therapeutics. 2019; 9(1):248-251

and open arm time (OE\% and OT\%). The formulae of OE $\%=$ $\mathrm{OE} /(\mathrm{OE}+\mathrm{CE}) \times 100 \%$ and $\mathrm{OT} \%=\mathrm{OT} /(\mathrm{OT}+\mathrm{CT}) \times 100 \%$ were calculated. After each trial, the apparatus was cleaned with $75 \%$ alcohol solution ${ }^{9}$.

\section{Open field test}

Open field test was conducted to rule out the possibility of motor disabilities. One hour after the probe trial, mice were relocated to an open field apparatus $(60 \mathrm{~cm} \times 40 \mathrm{~cm} \times 28$ $\mathrm{cm})$ with the flooring partitioned into 12 square. During the session of open field testing ( $5 \mathrm{~min}$ ), the number of rearing (vertical activity) and crossing (horizontal activity) responses were recorded manually 10 .

\section{Biochemical estimation}

\section{GABA assay}

Ensuing behavioral tests mice were beheaded and shifted onto dry ice. The rapid dissection of the brain was done and rinsed with ice cold normal saline $(0.9 \%$ sodium chloride) and frozen till the biochemical estimation. The frozen mouse brain tissue was homogenized in $10 \mathrm{vol}(\mathrm{w} / \mathrm{v})$ of ice normal saline. The homogenate was centrifuged at $3000 \mathrm{rpm}$ at $4^{\circ}$ for $10 \mathrm{~min}$ and the supernatant was collected. GABA levels in the brain were estimated using the GABA ELISA kit (Aviva Systems Biology, CA, USA). The GABA contents were expressed as microgram per kilogram of brain.

\section{Statistical analysis}

Results were expressed as mean \pm S.E.M. The data were analyzed by one way analysis of co-variance (ANCOVA) tracked by Tukey's multiple comparison tests. Probability values less than 0.05 were considered statistically significant in all the cases.

\section{RESULTS AND DISCUSSION}

\section{Effect of cardamonin treatment on performance of EPM}

Results were obtained from the arm entry experiments and the percentages of open arm entry and open arm time were compared. One way ANCOVA followed by post-hoc test demonstrated that medium $(5.0 \mathrm{mg} / \mathrm{kg})$ and high dose $(10.0$ $\mathrm{mg} / \mathrm{kg})$ cardamonin and estazolam $(1.5 \mathrm{mg} / \mathrm{kg})$ significantly $(\mathrm{p}<0.0001)$ increased 0T\% $[\mathrm{F}(4,25)=256.80, \mathrm{p}<0.0001$, $\left.\mathrm{R}^{2}=0.9762\right]$ and $\mathrm{OE} \%\left[\mathrm{~F}(4,25)=184.90, \mathrm{p}<0.0001, \mathrm{R}^{2}=\right.$ 0.9673] compared to respective vehicle control group. Treatment with cardamonin $(2.5 \mathrm{mg} / \mathrm{kg})$ did not influence OE\% and $0 \mathrm{~T} \%$ (Figure 1). 


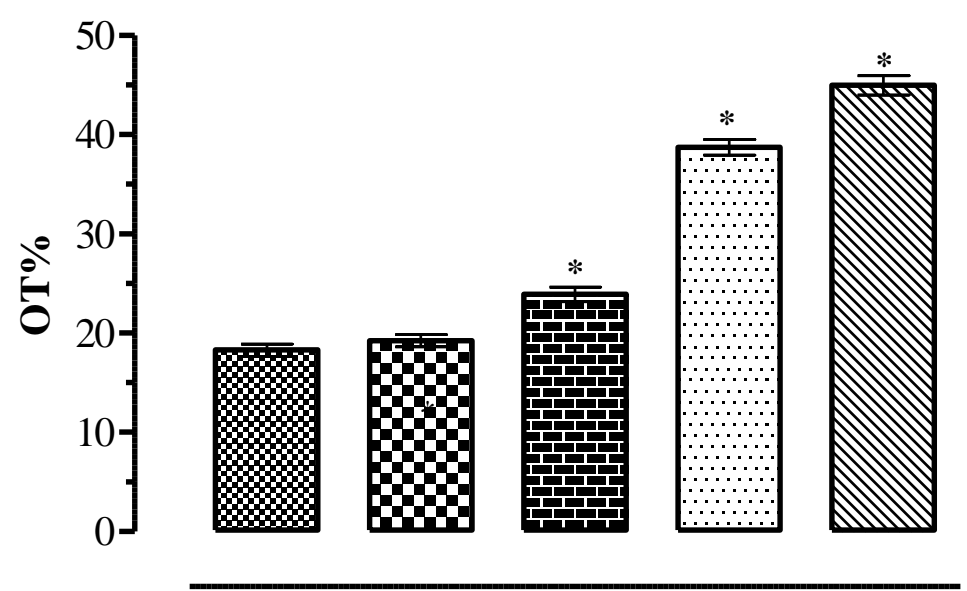

$\$ \mathbf{V C}$

Car $(2.5 \mathrm{mg} / \mathrm{kg})$

$\operatorname{Car}(5.0 \mathrm{mg} / \mathrm{kg})$

$\ldots \operatorname{Car}(10.0 \mathrm{mg} / \mathrm{kg})$

Estazolam $(1.5 \mathrm{mg} / \mathrm{kg})$

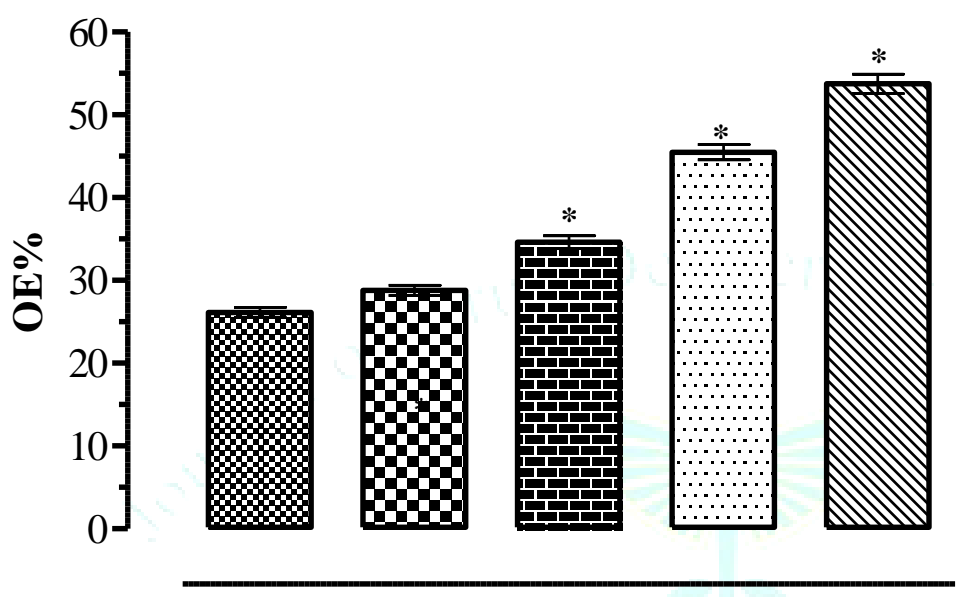

B VC

표 Car $(2.5 \mathrm{mg} / \mathrm{kg})$

무담 $\operatorname{Car}(5.0 \mathrm{mg} / \mathrm{kg})$

$\cdots$ Car $(10.0 \mathrm{mg} / \mathrm{kg})$

NDV Estazolam (1.5 mg/kg)

Figure 1: Effects of cardamonin on $\mathrm{OE} \%$ and $\mathrm{OT} \%$ in elevated plus maze apparatus.

Results are expressed as Mean \pm S.E.M.; $n=6$ in each group. Data was analyzed by one way repeat measure ANCOVA followed by Tuckey's multiple comparison test. Significance: " $p<0.0001$ when compared with VC group, Car: Cardamonin treated group; VC: Vehicle control.

\section{Effect of cardamonin on locomotor activity in open field test}

Motivational difference in the training period may relate for differences in inhibitory avoidance at testing. Hence open field study was performed to evaluate locomotor ability of the animals that would alter escape latency. One way
ANCOVA of open field data revealed that none of the treatment alter the number of crossing or rearing responses in a subsequent open field test session, signifying no influence on gross locomotor movement at testing $[\mathrm{F}(4,25)$ $\left.=0.12, \mathrm{p}=0.9893, \mathrm{R}^{2}=0.0188\right]$ and number of rearing $[\mathrm{F}(4$, $\left.25)=2.89, \mathrm{p}=0.9859, \mathrm{R}^{2}=0.3164\right]$ (Table 1$)$.

Table 1: Effects of cardamonin on locomotor activity and number of rearing in open field test.

\begin{tabular}{llll}
\hline Group & Treatment & No. of locomotor counts & No. of rearings \\
\hline Vehicle control & Vehicle $(1 \mathrm{ml} / \mathrm{kg})$ & $123.38 \pm 3.01$ & $28.21 \pm 0.62$ \\
& Car $(2.5 \mathrm{mg} / \mathrm{kg})$ & $122.86 \pm 3.32$ & $30.66 \pm 0.57$ \\
Cardamonin treated & Car $(5.0 \mathrm{mg} / \mathrm{kg})$ & $124.37 \pm 2.96$ & $30.18 \pm 0.72$ \\
& Car $(10.0 \mathrm{mg} / \mathrm{kg})$ & $122.40 \pm 3.57$ & $28.90 \pm 0.68$ \\
Standard & Estazolam $(1.5 \mathrm{mg} / \mathrm{kg})$ & $125.07 \pm 2.88$ & $30.54 \pm 0.59$
\end{tabular}

Results are expressed as Mean \pm S.E.M.; $\mathrm{n}=6$ in each group. Data was analyzed by one way repeat measure ANCOVA followed by Tuckey's multiple comparison test. Car: Cardamonin treated group. 


\section{Estimation of effect of cardamonin on brain GABAergic} activity

Treatment with cardamonin (5.0 and $10.0 \mathrm{mg} / \mathrm{kg}$ ) and estazolam $(1.5 \mathrm{mg} / \mathrm{kg})$ significantly increased levels of GABA in brain of treated mice $(\mathrm{p}<0.0001)$ compared to control mice. Treatment with cardamonin $(2.5 \mathrm{mg} / \mathrm{kg})$ did not influence levels of GABA $\left[F(4,25)=415.50, p<0.0001, R^{2}=\right.$ 0.9852] (Figure 2).

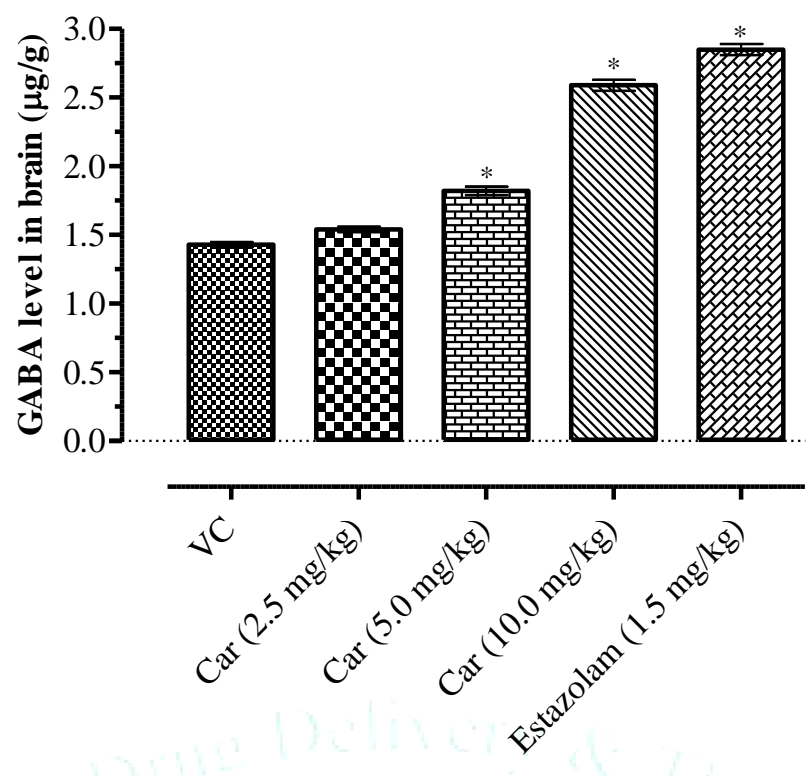

Treatment

Figure 2: Effects of cardamonin on GABA levels in brain of mice.

Results are expressed as Mean \pm S.E.M.; $n=6$ in each group. Data was analyzed by one way repeat measure ANCOVA followed by Tuckey's multiple comparison test. Significance: ${ }^{*} p<0.0001$ when compared with VC group, Car: Cardamonin treated group; VC: Vehicle control.

Anxiety disorders often accompany the abnormal expression of neurotransmitter such as NE, DA, 5-HT and GABA. GABA has been considered the major inhibitory neurotransmitter in the mammalian central nervous system, and enhanced GABAergic can be effective in treating anxiety disorders ${ }^{11}$. In this study, whereas the GABA level of cardamonin treated group at medium- and high-dose were significantly increased, indicating that cardamonin increases the GABA to inhibit the excitability of the central nervous system. In conclusion, this study indicated anxiolytic potency of cardamonin and its action mechanism of increasing GABA and future research will aim to offer more insights into this feature.

\section{REFERENCES}

1. Reynolds E, Brain and mind: a challenge for WHO, Lancet, 2003; 361(9373):1924-1925

2. Seligman MEP, Walker EF, Rosenhan DL. Abnormal Psychology. Fourth ed. New York: W.W. Norton and Company; 2000. P 183185.

3. Mesfin M, Asres K, Shibeshi W, Evaluation of anxiolytic activity of the essential oil of the aerial part of Foeniculum vulgareMiller in mice, BMC Complement Altern Med, 2014; 14(1):310-312.

4. Siddiq A, Younus I, The Radish, Raphanus sativus L. Var. caudatus reduces anxiety-like behavior in mice, Metabolic Brain Disease, 2018; 33:1255-1260.
5. Bheemasankara RC, Namosiva RT, Suryaprakasam, S, Cardamonin and alpinetin from the seeds of Amomum subulatum, Planta Medica 1976; 29(1):391-392.

6. Ping CP, Mohamad TAST, Akhtar MA et al., Antinociceptive effects of cardamonin in mice: possible involvement of TRPV1, glutamate, and opioid receptors, Molecules 2018; 23(1):22372239.

7. Peng S, Hou Y, Yao J, Fang J, Activation of Nrf2-driven antioxidant enzymes 1 by cardamonin confers neuroprotection of PC12 cells against oxidative damage, Food Funct, 2017; 228(3):997-1007.

8. Sambasevam Y, Farouk AAO, Mohamad TAST et al., Cardamonin attenuates hyperalgesia and allodynia in a mouse model of chronic constriction injury-induced neuropathic pain: Possible involvement of the opioid system, Eur J Pharmacol, 2017. 5(796):32-38.

9. Sidor MM, Rilett K, Foster JA, Validation of an automated system for measuring anxiety-related behaviours in the elevated plus maze. J Neurosci Methods, 2010; 188(1):7-13.

10. Bhutada $\mathrm{P}$, Mundhada $\mathrm{Y}$, Bansod K et al., Protection of cholinergic and antioxidant system contributes to the effect of berberine ameliorating memory dysfunction in rat model of streptozotocin-induced diabetes, Behav Brain Res, 2011; 220(1):30e41.

11. Macdonald RL, Bianchi MT. Encyclopedia of the neurological sciences: gamma aminobutyric acid (GABA). First ed. New York: Elsevier Science; 2003. P. 204-209. 